\title{
PLANEJAMENTO E ELABORAÇÃO DE UMA POLÍTICA DE INDEXAÇÃO PARA BIBLIOTECAS UNIVERSITÁRIAS: UM ESTUDO REALIZADO A PARTIR DA ANÁLISE DA INDEXAÇÃO E DA RECUPERAÇÃO DA INFORMAÇÃO EM CATÁLOGO ONLINE
}

Francisco Edvander Pires Santos

Bibliotecário da Universidade Federal do Ceará

edvanderpires@gmail.com

Guaracy Araújo Santiago Martins

Bibliotecária da Universidade Federal do Ceará guaracy@ufc.br

Irlana Mendes de Araújo

Bibliotecária da Universidade Federal do Ceará

irlanaaraujo@gmail.com

Juliana Soares Lima

Bibliotecária da Universidade Federal do Ceará

julia10br@gmail.com

Kalline Yasmin Soares Feitosa

Bibliotecária da Universidade Federal do Ceará kallineyasmin@gmail.com

Laninelvia Mesquita de Deus Peixoto

Bibliotecária da Universidade Federal do Ceará

lanededeus@ufc.br

Osvaldêmia Maria Lucena Maia

Diretora da Divisão de Processo Técnico

Universidade Federal do Ceará

demia@ufc.br

\section{Resumo}

Apresenta a teoria e a prática da indexação em bibliotecas universitárias, com foco na qualidade nos processos de representação e recuperação da informação em catálogo online. Traz como procedimentos metodológicos: a aplicação de questionário junto a bibliotecários, a pesquisa bibliográfica e a análise de conteúdo. Analisa os aspectos levados em consideração no planejamento e na elaboração de uma política de indexação, tendo como base os trabalhos desenvolvidos pelos autores num sistema de bibliotecas universitárias. Discorre acerca das principais definições e dos principais critérios de indexação, sob a perspectiva da atribuição de termos descritores e de busca no catálogo online. A partir das buscas realizadas no catálogo online, analisa o nível de revocação com a finalidade de exemplificar as ocorrências encontradas na pesquisa, na 
tentativa de propor critérios que embasaram a elaboração de uma política de indexação para o referido sistema de bibliotecas.

Palavras-chave: Indexação. Recuperação da informação. Estratégias de busca. Revocação. Bibliotecas universitárias.

\section{INTRODUÇÃO}

A relação entre indexação e busca nos catálogos online de bibliotecas universitárias tem sido objeto de estudo de uma comissão formada por bibliotecários(as) catalogadores(as) na instituição de ensino onde atuamos, principalmente no que concerne à qualidade na indexação visando a uma busca eficiente e eficaz por parte dos usuários. E é justamente com a finalidade de compartilhar experiências em nosso ambiente de trabalho que propomos uma discussão acerca da padronização no processo de indexação, mais especificamente por meio de uma política, e do nível de revocação identificado na busca no catálogo online.

Temos observado que os processos de representação e recuperação da informação têm criado uma relação cada vez maior entre o acervo das bibliotecas, a prática da indexação e as exigências dos usuários, principalmente devido à automação dos catálogos, à existência de publicações em formato eletrônico e à consequente alimentação de repositórios digitais. Sendo assim, a maneira como se dá o tratamento técnico da informação deve suprir eficiente e eficazmente as necessidades de busca e de informação dos usuários, independente de qual seja o público-alvo ao qual se destina a biblioteca ou o centro de documentação. Nesse contexto, este estudo é resultado do desenvolvimento de nossas atividades no processamento técnico da informação e na prática do serviço de referência, mais especificamente num sistema de bibliotecas universitárias.

A necessidade de padronização da rotina e dos procedimentos de indexação no ambiente de trabalho onde atuamos motivou-nos a desenvolver uma política de indexação na tentativa de nortear a práxis bibliotecária e a busca do usuário no catálogo online. A estratégia definida para compor a política foi a de analisar o nível de revocação do sistema de recuperação da informação (catálogo online). Assim, a consistência da política nos possibilitou elaborar diretrizes com base na realidade das bibliotecas, visando atender às reais necessidades de busca dos usuários. Para tanto, aliamos a prática no processamento técnico da informação com o serviço de referência, tomando como base, especificamente, três das oito etapas do processo de referência definidas por Grogan (1995), a saber: estratégia de busca, processo de busca e resposta ao usuário. Por conseguinte, atender e ouvir o usuário tem nos possibilitado uma indexação de qualidade e um maior controle sobre a revocação do sistema (LANCASTER, 2004). Ao conhecer as características das publicações e a demanda de informação por parte da comunidade usuária, tornamo-nos aptos para atribuir termos descritores que sejam mais apropriados à representação do conteúdo do documento.

Como embasamento teórico, recorremos a publicações que trazem como tema central: a representação temática da informação; a teoria da indexação; o roteiro para a elaboração de uma política de indexação; e as linguagens documentárias, visando subsidiar o planejamento e a estruturação da política e desta publicação.

\section{TEORIA E PRÁTICA DA} INDEXAÇÃO 
Alguns dos principais conceitos de indexação remontam de décadas atrás, porém é nítido que a sua prática tem se aperfeiçoado com o passar do tempo, tendo em vista os acervos físicos e digitais que compõem atualmente as bibliotecas e os centros de documentação. Chaumier (1988, p. 63) considera a indexação como sendo:

[...] a parte mais importante da análise documentária. Conseqüentemente, é ela que condiciona o valor de um sistema documentário. Uma indexação inadequada ou uma indexação insuficiente representam 90\% das causas essenciais para a aparição de "ruídos" ou de "silêncios" em uma pesquisa. Os $10 \%$ restantes serão devidos a causas mecânicas [...]

Bentes Pinto (2001, p. 226), por sua vez, define a indexação documentária como:

[...] um conjunto de atividades que consiste em identificar, nos documentos, os seus Traços descritivos (TD's) ou macroproposições e, em seguida, extrair os elementos/descritores (sintagmas) indicadores de seu conteúdo, visando à sua recuperação posterior [...] No caso dos conceitos e das palavras-chave, eles podem ser extraídos do documento mesmo ou ainda atribuídos a partir de outras fontes, como por exemplo, as Linguagens documentárias (LD's).

Faz-se necessário que o indexador conheça as características de cada documento, bem como a demanda por informação de seus usuários, para que, assim, possa atribuir termos descritores que sejam mais apropriados à representação do conteúdo informacional. É preciso, então, que as etapas de indexação sejam rigorosamente seguidas, a saber: a análise conceitual do documento, a tradução para a linguagem do sistema e o controle de qualidade de todo o processo (BENTES PINTO, 2001). Essas etapas podem ser consideradas como sendo

interligadas

interdependentes.

Aplicando as etapas da indexação ao ambiente das bibliotecas universitárias, para que determinado documento seja incorporado ao Sistema de Recuperação da Informação (SRI), o indexador deve analisá-lo conceitualmente baseado na definição explícita da comunidade acadêmica à qual o documento ou a publicação se destina. A partir dessa informação, é possível inserir no sistema os termos mais relevantes que representam o conteúdo analisado. Por conseguinte, deve-se atentar para a etapa de tradução, na qual a linguagem natural será convertida para a linguagem controlada do sistema.

Contudo, é de suma importância que o sistema seja periodicamente submetido a um criterioso controle de qualidade, visando avaliar se os termos estão realmente suprindo as necessidades de busca dos usuários. E é nessa etapa que se deve verificar se há algum problema em relação à revocação e/ou precisão do sistema, dependendo de sua dimensão de indexação: exaustiva ou específica (LANCASTER, 2004). A exaustividade na indexação gera maior revocação e menor precisão no momento da pesquisa, podendo ocorrer de informações irrelevantes também serem recuperadas causando o "ruído" de que trata Chaumier (1988) -, enquanto que a especificidade possibilita uma maior precisão e menor revocação no momento da busca, mas podendo deixar de recuperar algum conteúdo importante, gerando o "silêncio" de que trata Chaumier (1988).

Corroborando essa aplicação, Bentes Pinto (2001, p. 227-228) conceitua as dimensões da indexação:

A indexação exaustiva procura extrair do documento o maior número de conceitos de forma a cobrir o seu conteúdo da maneira mais completa possível [...] A indexação específica, como o nome o diz, leva em consideração os conceitos específicos em função dos temas 
tratados no documento. Esta maneira de indexar diz respeito à profundidade com a qual o conteúdo de um documento é tratado.

Conforme explicitado, exaustividade e especificidade trazem como consequência mais dois conceitos importantes para o indexador: revocação e precisão. Segundo Carneiro (1985, p. 234, grifo da autora),

A revocação se relaciona com a capacidade do sistema em assegurar a recuperação de um número desejável de documentos relevantes e a precisão se relaciona à capacidade do sistema em impedir a recuperação de documentos não-relevantes.

Para que o processo de indexação seja executado de uma maneira consistente na instituição, Rubi, Fujita e Boccato (2012, p. 221-222) destacam a formação do indexador como um dos pilares desse processo:

A indexação deve ser realizada pelo bibliotecário indexador ou pelo bibliotecário catalogador que também desenvolve essa atividade. $\mathrm{O}$ indexador deverá ter conhecimentos das áreas de assuntos tratados, da linguagem de indexação adotada pelo sistema e das necessidades informacionais dos usuários, bom nível de concentração e capacidade e compreensão de leitura. Além disso, deve agir com imparcialidade [na medida do possível] e possuir fidelidade na prática desse processo [...] O indexador deve participar em programas de capacitação ofertados pela biblioteca/instituição sobre indexação e sobre temas correlatos a esse processo.

$\mathrm{Na}$ formação do perfil do indexador, bem como no desenvolvimento de suas competências e atividades, é importante considerar o catálogo online da biblioteca universitária, em nível institucional, como uma legítima base de dados, e não apenas com informações inseridas aleatória e mecanicamente. Assim, conforme Rubi (2012, p. 171),

Essa dimensão assumida pelo catálogo deve fazer com que o bibliotecário assuma uma nova responsabilidade pautada no compromisso com a construção de catálogos condizentes com a realidade não somente de sua comunidade usuária local, mas também de uma comunidade usuária potencial virtual [em nível de sistema de bibliotecas, por exemplo], cada vez mais exigente.

Essa exigência do usuário tende a fazer com que o bibliotecário atue com uma postura multifacetada, simultaneamente como catalogador e indexador, pois além da descrição fidedigna do conteúdo do documento (em nível de indexação), farse-á necessário explorar os recursos disponibilizados pelo sistema (em nível de catalogação), tais como inserção de imagens representando as capas dos livros, links, arquivos em PDF contendo sumário ou o trabalho na íntegra (no caso de teses e dissertações), dentre outros. É a interação catálogo e usuário sendo cada vez mais valorizada, com foco nas reais necessidades informacionais do usuário. Isso faz com que o bibliotecário catalogador passe a adotar uma "postura compromissada semelhante à de um indexador que trabalha na produção de bases de dados." (RUBI, 2012, p. 173). Para Boccato (2012, p. 147),

Tais profissionais devem ser valorizados em suas funções, considerando-se os conhecimentos prévios, as visões de mundo e os conceitos e linguagens adquiridos durante seu processo de interrelação com o meio social, como fatores contribuintes para a formação e desempenho satisfatório de um sistema de recuperação da informação mediante o uso de linguagens documentárias, a exemplo dos tesauros.

Além disso, é preciso que todos os procedimentos referentes à atividade de 
indexação na instituição sejam padronizados e documentados, seja por meio de manuais, políticas e/ou diretrizes. Nesse sentido, a importância da elaboração de uma política de indexação, por exemplo, apresenta-se em vários fatores, e um deles é a necessidade de garantia de um padrão permanente de qualidade e excelência no processo de representação da informação, tendo como resultado uma recuperação da informação igualmente de qualidade. Outro elemento importante é quanto à organização do conhecimento como fator de contribuição para o avanço tecnológico e científico, no sentido de que a política de indexação normalize os procedimentos e o estabelecimento de linguagens documentárias.

Dessa forma, Nunes (2004, p. 55, grifo nosso) define política de indexação como sendo "uma diretriz que explicita as escolhas técnicas (por isso política) que a biblioteca faz (e os bibliotecários precisam observar em suas rotinas), considerando fundamentalmente duas variáveis: o seu usuário e o seu acervo." Segundo Carneiro (1985, p. 221), uma política de indexação serve como um guia para a tomada de decisão e deve levar em consideração os seguintes fatores: características e objetivos da organização, identificação da comunidade usuária e disponibilidade de recursos humanos, materiais e financeiros. Nesse contexto, todos os esforços devem ser direcionados para uma boa indexação e, para que isso ocorra, é necessário que muitas singularidades sejam observadas, tais como: o indexador, as técnicas de indexação, os usuários do sistema, o acervo e a instituição. Assim, a política de indexação deve ser vista como uma filosofia a ser seguida (RUBI, 2008, p. 50, citada por BOCCATO, 2012, p. 150).

Uma boa qualidade na indexação permite ao usuário a recuperação de qualquer documento em um SRI, visando obter resultados positivos. De acordo com Strehl (1998, p. 329), “o principal objetivo de um serviço de indexação de qualidade é assegurar a recuperação de qualquer documento ou informação no momento em que o usuário busca um assunto em um sistema de informações." Nesse sentido, corrobora-se que

Um dos maiores problemas encontrados em um S.R.I são as diferentes linguagens usadas pelo autor, pelo usuário e pelo próprio S.R.I. O bibliotecário responsável deve estabelecer uma relação entre estas três diferentes linguagens, fazendo com que a unidade lexical utilizada como descritor, seja a mais próxima possível daquela utilizada pelo usuário. (VAN DER LAAN; ALVORCEM, 2007, p. 110).

$\mathrm{O}$ processo de indexação com qualidade envolve a análise de assunto, que é orientada pela ênfase no conteúdo do documento e pela ênfase no usuário potencial do documento a ser indexado. Para que essa análise seja feita, é necessária uma leitura documentária realizada a partir do exame de partes do documento que possibilitarão a identificação e seleção dos assuntos abordados, sendo as principais partes:

$\checkmark$ Introdução: enfatizar os objetivos do texto;

$\checkmark$ Leitura das frases introdutórias de parágrafos e capítulos;

$\checkmark$ Metodologia: centrar nas técnicas, instrumentos e procedimentos adotados na realização da pesquisa; no local e ambiência em que esta se passa, assim como no objeto da pesquisa; no caso de população, observação de gênero, cor, faixa etária etc.;

$\checkmark$ Conclusão: leitura de toda a conclusão, sendo muito importante para os objetivos propostos;

$\checkmark$ Gráficos, tabelas, diferenciação tipográfica etc.

$\checkmark$ Título, subtítulo, resumo e palavras-chave podem ser verificados 
na fase final da leitura, a fim de evitar que o indexador seja influenciado de imediato por esses elementos, já que os mesmos muitas vezes não refletem a veracidade do conteúdo dos documentos (garantia literária).

Assim, é preciso realizar a identificação dos conceitos abordados no conteúdo do documento de acordo com a área de conhecimento. A partir dessa identificação, será possível selecionar os conceitos que realmente estão abordados no conteúdo do documento e, portanto, válidos para serem indexados. A qualidade na indexação irá se refletir no uso de descritores convenientes com a linguagem de indexação (controlada) adotada pelo SRI.

Para os termos que representem novos conceitos, verificamos sempre a sua aceitação em outros instrumentos, tais como: sistemas de classificação; dicionários e enciclopédias reconhecidas; tesauros especializados e bases de dados fidedignas. Quando e se necessário, consultamos especialistas no assunto, e, nos casos em que não encontramos conceitos presentes nos tesauros das bases de dados, os referidos conceitos acabam sendo expressos por descritores que venham a ser incluídos na linguagem de indexação. Além disso, também consideramos importante pesquisar as ocorrências do termo no Google, pois poderá trazer qualidade à indexação na medida em que será possível verificar a quantidade de uso de um determinado descritor na Web, validando o termo ao cadastrá-lo na base de autoridades do SRI; e consultar bases de dados especializadas, portais institucionais de periódicos, teses e dissertações já publicadas sobre um determinado assunto ou até mesmo as áreas do conhecimento conforme o Conselho Nacional de Desenvolvimento Científico e Tecnológico (CNPq), dentre outras ações que variam de acordo com o perfil de cada indexador.

\section{PROCEDIMENTOS METODOLÓGICOS}

Como metodologia inicial adotada, foi elaborado e compartilhado um questionário dentre os(as) bibliotecários(as) catalogadores(as) do sistema de bibliotecas onde atuamos. Com as respostas obtidas, foi possível delimitar a consistência da política de indexação e tomar conhecimento da realidade de indexação em cada biblioteca, como a identificação da comunidade usuária, da cobertura de assuntos, da seleção de documentos e dos tipos de materiais incorporados ao acervo, além da escolha da linguagem e dos critérios de indexação mais adequados a algumas das grandes áreas do conhecimento.

Obtivemos questionários respondidos por bibliotecários(as) das áreas de Ciências Humanas, Exatas, Ambientais e da Saúde. Dentre as perguntas que constaram no questionário, destacamos: quais os instrumentos auxiliares utilizados para a indexação na área de atuação do(a) bibliotecário(a); quantos descritores poderiam ser atribuídos a cada documento; de quais partes da obra o(a) bibliotecário(a) extrai os conceitos para a indexação do documento; de que forma o(a) bibliotecário(a) indexa um termo não encontrado nas fontes de pesquisa de assuntos autorizados; e se já havia sido feito na biblioteca algum estudo voltado para a recuperação da informação.

Recorremos também à pesquisa bibliográfica e à análise de conteúdo a partir das informações disponíveis no catálogo online da biblioteca universitária onde trabalhamos. Foi analisado o processo de indexação e de busca, na tentativa de identificarmos a dimensão, o nível de revocação e a precisão na indexação, com base em exemplos aleatórios pesquisados no SRI que nos conduziram às ocorrências encontradas. Nesse sentido, seguimos o exposto por Cavalcante, Calixto e Pinheiro (2014, p. 16): 
Durante a etapa da exploração do material, o investigador busca encontrar categorias que são expressões ou palavras significativas em função das quais o conteúdo de uma fala [em nosso caso, de um SRI] será organizado. A categorização, para Minayo (2007), consiste num processo de redução do texto às palavras e expressões significativas [...] Finalmente, o pesquisador realiza a classificação e a agregação dos dados, escolhendo as categorias teóricas ou empíricas, responsáveis pela especificação do tema (BARDIN, 1977). A partir daí, o analista propõe inferências e realiza interpretações, inter-relacionando-as com o quadro teórico desenhado inicialmente ou abre outras pistas em torno de novas dimensões teóricas e interpretativas, sugerida pela leitura do material (MINAYO, 2007).

Portanto, para a definição dos critérios contemplados nas diretrizes para a indexação, foram levados em consideração a análise das repostas ao questionário, o processo de indexação nas bibliotecas, a recuperação da informação no catálogo online e a análise de conteúdo tendo como base os registros recuperados na busca e as ocorrências encontradas (constatações) na pesquisa no SRI. Além disso, os seguintes fatores foram observados para levarmos nosso estudo adiante: a quantidade de registros recuperados na busca livre e por assunto; os tipos de obras recuperados; a dimensão da indexação trabalhada; o nível de revocação da pesquisa e a comparação se todos os registros versavam, ou não, sobre o assunto pesquisado.

\section{CRITÉRIOS NA ELABORAÇÃO DA POLÍTICA DE INDEXAÇÃ̃O}

Inicialmente, definimos que indexar sob termos relevantes e/ou autorizados extraídos do próprio título do documento iria proporcionar ao usuário uma maior possibilidade de recuperação da informação na busca por assunto, tendo em vista a quantidade dos resultados filtrados. Comprovamos essa afirmação na quantidade exata de registros recuperados na busca livre e por assunto, quando comparamos a quantidade de ocorrências encontradas, do termo "nanotubos de carbono", um termo indexado sob uma dimensão específica que trouxe um baixo nível de revocação e alta precisão na busca.

Também observamos a importância de qualificar um determinado assunto, no sentido de atribuir qualificadores entre parênteses ou nos subcampos do sistema. Os qualificadores acabam determinando o contexto de uso do assunto, de acordo com a área do conhecimento, por exemplo. O uso de unitermos também foi considerado de extrema importância na atribuição de qualificadores, pois observamos que a indexação apenas por unitermo poderá resultar numa alta revocação e na ausência de precisão no momento da busca, a exemplo do que ocorreu na pesquisa feita pelo termo "razão", que utilizamos na política sob o contexto da Filosofia, mas que também recuperou registros nas áreas da Psicologia, Matemática e Direito, esta última devido à remissiva "ver também" em termos equivalentes.

Ao atribuirmos qualificadores, evitam-se e/ou reduzem-se os casos de ambiguidade e polissemia, que também levamos em consideração na composição da política. Foi de fundamental importância analisar detalhadamente a pesquisa realizada pelo termo "indexação", com registros recuperados nas áreas de Biblioteconomia e Economia, porém com a recuperação de registros da área da Saúde e Ciências Biológicas, em virtude de remissivas existentes no termo "classificação", bastante comum a essas áreas. Recomendamos, então, que o indexador atentasse para o significado de um mesmo termo para áreas distintas, a fim de evitar "confusões" trazidas pela ambiguidade e polissemia, tanto na 
representação quanto na recuperação da informação.

Traçando um paralelo, chamamos a atenção para o uso das remissivas na indexação. Inicialmente, abordamos os casos da remissiva "ver", que implica na indexação por termos considerados sinônimos. Como exemplo, citamos os termos "distúrbios do sono" (termo autorizado) e "transtornos do sono" (termo em linguagem natural, porém passível de busca pelo usuário). Nesse caso, constatamos que o nível de revocação foi baixo, tendo em vista a dimensão da indexação ser específica, o que possibilitou uma recuperação precisa no momento da pesquisa. Já na remissiva "ver também", utilizada com termos que se relacionam entre si, constatamos a existência de alta revocação nos exemplos que escolhemos: "gestão da qualidade", "benchmarking" e "teoria do conhecimento".

Consideramos a dimensão da indexação exaustiva no caso em que o termo "benchmarking" fora indexado como remissiva "ver também" do termo tópico "gestão da qualidade", fazendo com que na busca pelo termo "benchmarking" também fossem recuperadas obras que versam sobre "gestão da qualidade", mas nem sempre uma obra sobre "gestão da qualidade" abordará o tema "benchmarking", e isso acabou gerando uma alta revocação na pesquisa, seguida de não precisão. A alta revocação também foi constatada quando pesquisamos por "teoria do conhecimento" (sinônimo de "Epistemologia"), recuperando registros irrelevantes na pesquisa, pois a grande quantidade de termos inseridos na remissiva "ver também" não contemplava o referido assunto, tornando a indexação exaustiva.

Como orientações essenciais ao trabalho de qualidade do indexador, inserimos uma seção unicamente tratando sobre o uso das notas explicativas no cadastro de autoridade de assunto. As notas foram divididas em: notas de remissiva, notas de conceituação e notas restritas ao indexador. Entendemos que as notas de remissiva complementam o uso da remissiva "ver também" ao explicarem as relações entre os termos, servindo de auxílio tanto para o indexador (ao esclarecer dúvidas sobre o uso de um determinado termo, na decisão de escolher o termo mais adequado para indexar) quanto para o usuário em potencial (que poderá pesquisar por autoridades no catálogo online), como os(as) bibliotecários(as) de outras instituições, por exemplo. Quanto às notas de conceituação, a decisão foi a de inserir definições sobre o termo descritor, com a devida menção da fonte, já às notas restritas ao indexador, atribuímos a função de explicitar orientações de como as subdivisões dos campos devem ser utilizadas pelo indexador, ressaltando que o usuário que pesquisar no catálogo online de autoridades não terá acesso ao texto. A função de cada nota na política de indexação foi definida de acordo com os manuais de catalogação e de tesauros disponibilizados pelo SRI com o qual trabalhamos.

Abordamos ainda a equivalência entre termos, subdividindo-a em: sinônimos na língua vernácula, casos de estrangeirismo ou aportuguesamento, busca por dois (ou mais) idiomas e flexões dos termos descritores. Nos casos em que ocorrem sinônimos na língua vernácula, reiteramos o exposto acerca da remissiva "ver", pois a equivalência entre os termos se dá ao trazer da linguagem natural o termo equivalente não autorizado. Como exemplo, inserimos na política os termos "cefaleia" e "dor de cabeça", com a possibilidade de ambos serem recuperados no catálogo online se indexados como termos equivalentes, sob uma dimensão específica e baixo nível de revocação na pesquisa. Nos casos de estrangeirismo ou aportuguesamento, ilustramos, como exemplo, o termo "layout", também escrito como "leiaute", 
com dimensão de indexação específica, baixo nível de revocação e recuperação de obras que também versavam sobre "design", devido à existência de remissivas.

$\mathrm{Na}$ busca por dois (ou mais) idiomas, constatamos que, ao indexar um determinado termo proveniente de língua estrangeira, o indexador deverá atentar para o uso desse termo na comunidade à qual a publicação se destina. Se houver termo equivalente na língua portuguesa, recomendamos inseri-lo como termo equivalente, o mesmo raciocínio valendo para os termos provenientes da língua portuguesa que tenham termos equivalentes na língua estrangeira (desde que o termo seja amplamente utilizado pela comunidade usuária). Analisamos aqui a possibilidade de cruzamento entre os termos na busca, que implica diretamente no nível de revocação e precisão no momento da pesquisa. Exemplificando, consideramos a indexação específica com o termo "teoria de resposta ao item", tendo como equivalência o termo "item response theory". Nesse caso, foram recuperadas apenas as obras em língua portuguesa; portanto, não houve o cruzamento de equivalência entre os termos (português inglês), deixando, assim, uma lacuna se o usuário pesquisar pelo termo em inglês.

Finalizando o tópico sobre a equivalência entre os termos, enfatizamos os casos de flexões dos descritores, em número (singular e plural), gênero (masculino e feminino) e grau (aumentativo e diminutivo). $\mathrm{O}$ exemplo escolhido foi "correntes elétricas", que também identificamos no sistema indexação feita sob "corrente elétrica". Chamamos a atenção do indexador para que houvesse a transferência de autoridade, unificando sob um único termo as disparidades encontradas no SRI, padronizando, assim, os termos em número, gênero e grau de acordo com catálogos e tesauros existentes, e/ou com a linguagem amplamente utilizada pela comunidade usuária da biblioteca. Nesse sentido, ressaltamos a importância de padronizar os termos na base de autoridades do SRI, a fim de facilitar a escolha do indexador no momento da representação do conteúdo da obra, bem como "enxugar" os termos repetidos (com o mesmo significado e/ou contexto de uso) no sistema, visando evitar uma alta revocação na indexação, ou seja, no momento em que o indexador pesquisará o termo no SRI.

Como último tópico da política acerca dos critérios para indexação, foram abordados os demais tipos de autoridade de assunto: nome pessoal, entidade, evento e nome geográfico. $\mathrm{Na}$ indexação por nome pessoal, contemplamos a possibilidade de o usuário pesquisar obras de autoria de um determinado teórico, mas também de obras que tratassem sobre a vida ou algum assunto relacionado àquele autor. Como exemplo, escolhemos o termo "Vygotsky", com recuperação numa dimensão específica e baixo nível de revocação na pesquisa, recuperando registros sobre e escritos por Vygotsky. Nos casos de entidade como assunto, pesquisamos por "CNPq", com registros recuperados sob uma dimensão exaustiva e com alto nível de revocação, ocasionado principalmente pelo fato desse termo não constar no campo de indexação em alguns dos registros que abordam, de alguma forma, o "CNPq" (como assunto e não como entidade responsável pela autoria de publicações), impossibilitando ao usuário recuperar a informação desejada filtrando a pesquisa por assunto.

O inverso ocorreu no caso de evento como assunto, cujo exemplo escolhido foi "congresso de energia". Ambas as possibilidades de recuperação foram possíveis: por assunto e por autoria, pois o termo constava no campo destinado à indexação. Já na indexação de nome geográfico, deparamo-nos com a não recuperação das preposições nos termos "ditadura militar no Brasil" e "literatura na Espanha". O sistema recuperou por 
palavras satisfatoriamente, desde que desprezássemos as preposições na pesquisa, o que interferiu diretamente no nível de revocação e na precisão da busca. Todas essas observações foram devidamente documentadas na política com o objetivo de ilustrar a forma como foi realizada a indexação, bem como as ocorrências encontradas na recuperação da informação no catálogo online. As ocorrências não significam necessariamente que toda a indexação de uma determinada biblioteca esteja sob a dimensão e/ou revocação encontrada, pois serviram apenas de exemplos para embasar os elementos da política e as orientações recomendadas para o indexador.

Seguindo esses critérios, ficou cada vez mais nítida a necessidade de padronização da rotina de trabalho do indexador, considerando que o catálogo online está disponível em nível institucional, ou seja, sob o domínio do ambiente da universidade, apesar de já haver casos em que sites de busca também recuperam os registros dos catálogos. Faz-se necessário, então, que as bibliotecas universitárias proporcionem ao usuário uma forma de acesso eficiente e eficaz às informações que constam no catálogo online, visando entregar ao usuário a sua resposta num menor tempo possível de busca.

\section{CONSIDERAÇÕES FINAIS}

Entendemos que discutir indexação, processo e estratégias de busca nos catálogos online de bibliotecas universitárias só tende a enriquecer nossa práxis bibliotecária. Nesse sentido, dedicamo-nos a estudar a recuperação da informação no catálogo online da instituição onde temos desempenhado nossas atividades. Constatamos a importância do bibliotecário como gerenciador (mediador) de todo o processo que envolve a catalogação e indexação de materiais bibliográficos, desde a etapa da aquisição até o estudo minucioso de como se dá a recuperação da informação.

Corroboramos e complementamos o exposto por Souza et al. (2015, [p. 1516]):

$\checkmark$ Que os sistemas automatizados permitam todas as formas de indexação, de busca e de recuperação de dados, uma vez que foram concebidos com a ideia de facilitar e agilizar $o$ acesso às informações disponíveis em qualquer lugar, do físico ao digital;

$\checkmark$ Que os(as) responsáveis pela indexação em sistemas de informação entendam a linguagem natural como dados informacionais relevantes, convertendo-as numa linguagem controlada se e sempre que possível;

$\checkmark$ Que se façam treinamentos constantes, mostrando aos usuários outras ferramentas de pesquisa, enfatizando os operadores booleanos AND/OR/NOT, assim como truncamentos que utilizam símbolos (*, \$, \% e?), que fazem complemento em prefixo, sufixo e entre letras, no qual possibilitam resultados mais satisfatórios;

$\checkmark$ Que se realizem pesquisas diretas com os usuários, aliando a práxis no processamento técnico da informação com o serviço de referência, com a finalidade de orientá-los em outros tipos de pesquisa, a exemplo das pesquisas avançadas.

Acrescentamos ainda os seguintes fatores:

$\checkmark$ Atualizações periódicas do SRI adotado pela instituição;

$\checkmark$ Aquisição de material eletrônico para compor o acervo das bibliotecas universitárias;

$\checkmark$ Desenvolvimento de hardwares, softwares e/ou aplicativos que contemplem a demanda na indexação de documentos em bibliotecas universitárias; $\checkmark$ Realização de testes contínuos de recuperação da informação no catálogo 
online, com a finalidade de alinhar os processos de indexação e busca;

$\checkmark$ Viabilização de pesquisa de opinião junto aos usuários com base na recuperação da informação;

$\checkmark$ Alinhamento da indexação no setor de processamento técnico da informação com as fichas catalográficas geradas por módulos automatizados disponibilizados na Internet, traduzindo para a linguagem do sistema os termos que irão constar nas fichas catalográficas da produção acadêmica; $\checkmark$ Análise periódica de relatórios e de estatísticas de materiais não encontrados, títulos ou registros não recuperados no momento da pesquisa do usuário, visando à adequação dos termos à linguagem dos usuários no cadastro de autoridades.

Contatamos, então, que a elaboração de uma política de indexação ainda se faz necessária no contexto institucional, tendo em vista que padroniza, norteia e traça critérios e/ou diretrizes para o trabalho do indexador e também para algumas das estratégias de busca adotadas pelos usuários.

\title{
PLANNING AND DEVELOPING AN INDEXING POLICY TO ACADEMIC LIBRARIES: A STUDY BASED ON ANALYSIS OF INDEXING PROCESS AND INFORMATION RETRIEVAL ON ONLINE CATALOG
}

\begin{abstract}
This study presents the indexing theory and practice in academic libraries, focusing on the quality of indexing and information retrieval from online catalog. In this respect, sending questionnaires to libraries, resorting to bibliographic research and doing a content analysis were used as scientific methods. This study also analyzes some aspects which were pointed out to plan and to carry an indexing policy out from works that were developed by the authors of this paper in academic libraries. It discusses the main definitions and criteria of indexing to choose a better keyword to index documents and to search for information on online catalog. Finally, it analyzes the results which were recovered (recall) after searching on online catalog, aiming to give some examples to be discussed along the indexing policy that was developed to the academic libraries where the authors of this paper have worked as librarians.
\end{abstract}

Keywords: Indexing. Information retrieval. Search strategies. Recall. Academic libraries.

\section{REFERENCIAS}

BARITÉ, Mario et al. Garantia literária: elementos para uma revisão crítica após um século. TransInformação, Campinas, v. 22, n. 2, p. 123-138, maio/ago. 2010. Disponível em: <http://periodicos.puccampinas.edu.br/seer/index.php/transinfo/ article/view/490/470>. Acesso em: 11 dez. 2015.

BENTES PINTO, Virgínia. Indexação documentária: uma forma de representação do conhecimento registrado. Perspectivas em Ciência da
Informação, Belo Horizonte, v. 6, n. 2, p. 223-234, jul./dez. 2001. Disponível em: <http://portaldeperiodicos.eci.ufmg.br/ind ex.php/pci/article/view/423/239>. Acesso em: 15 dez. 2015.

BOCCATO, Vera Regina Casari. A linguagem documentária em catálogos online para política de indexação. In: GIL LEIVA, Isidoro; FUJITA, Mariângela Spotti Lopes (Ed.). Política de Indexação. São Paulo: Cultura Acadêmica; Marília, SP: Oficina Universitária, 2012. cap. 5, p. 139-151. Disponível em: 
<http://www.marilia.unesp.br/Home/Publi cacoes/politica-de-indexacao_ebook.pdf $>$. Acesso em: 18 nov. 2015.

CARNEIRO, Marília Vidigal. Diretrizes para uma política de indexação. Revista da Escola de Biblioteconomia da UFMG, Belo Horizonte, v. 14, n. 2, p. 221-241, set. 1985. Disponível em: >. Acesso em: 23 mar. 2015.

CAVALCANTE, Ricardo Bezerra; CALIXTO, Pedro; PINHEIRO, Marta Macedo Kerr. Análise de conteúdo: considerações gerais, relações com a pergunta de pesquisa, possibilidades e limitações do método. Informação \& Sociedade: Estudos, João Pessoa, v. 24, n. 1, p. 13-18, jan./abr. 2014. Disponível em:

<http://www.ies.ufpb.br/ojs/index.php/ies/ article/download/10000/10871>. Acesso em: 09 ago. 2015.

CESARINO, Maria Augusta da Nóbrega. Sistemas de recuperação da informação. Revista da Escola de Biblioteconomia da UFMG, Belo Horizonte, v. 14, n. 2, p. 157-168, set. 1985. Disponível em: $<$ http://www.brapci.ufpr.br/documento.ph $\mathrm{p} ? \mathrm{dd} 0=0000009051 \& \mathrm{dd} 1=74 \mathrm{f} 4 \mathrm{c}>$.

Acesso em: 06 abr. 2015.

CHAUMIER, Jacques. Indexação: conceito, etapas e instrumentos. Revista Brasileira de Biblioteconomia e Documentação, São Paulo, v. 21, n. 1-2, p. 63-79, jan./jul. 1988. Disponível em: $<$ http://www.brapci.ufpr.br/documento.ph $\mathrm{p} ? \mathrm{dd} 0=0000011407 \& d d 1=6442 \mathrm{e}>$.

Acesso em: 10 abr. 2015.

CONSELHO NACIONAL DE DESENVOLVIMENTO CIENTÍFICO E TECNOLÓGICO. Tabela de áreas do conhecimento. Disponível em: <http://www.cnpq.br/documents/10157/1 86158/TabeladeAreasdoConhecimento.pd f>. Acesso em: 14 dez. 2015.
GROGAN, David Joseph. A prática do serviço de referência. Tradução: Antonio A. Briquet de Lemos. Brasília, DF: Briquet de Lemos/Livros, 1995.

LANCASTER, F. W. Indexação e resumos: teoria e prática. 2. ed. rev. atual. Brasília: Briquet de Lemos/Livros, 2004.

NUNES, Cláudio Omar Iahnke. Algumas considerações acerca da ausência de políticas de indexação em biblioteca Brasileiras. Biblos: Revista do Instituto de Ciências Humanas e da Informação, Rio Grande, n. 16, p. 55-61, 2004. Disponível em:

<http://www.seer.furg.br/biblos/article/vie w/411>. Acesso em: 05 abr. 2015.

OLIVEIRA, Carla Cristina Vieira de. A interação dos usuários da UFMG com o catálogo online do sistema Pergamum. 2008. 200 f. Dissertação (Mestrado em Ciência da Informação) - Escola de Ciência da Informação, Universidade Federal de Minas Gerais, Belo Horizonte, 2008. Disponível em:

<http://repositorio.cfb.org.br/bitstream/12 3456789/511/1/Carla\%20Cristina\%20Vie ira\%20de\%20Oliveira\%203.pdf>. Acesso em: 11 nov. 2015.

RUBI, Milena Polsinelli. Proposta para implantação de política de indexação em bibliotecas. In: GIL LEIVA, Isidoro; FUJITA, Mariângela Spotti Lopes (Ed.).

Política de Indexação. São Paulo: Cultura Acadêmica; Marília, SP: Oficina Universitária, 2012. cap. 7, p. 171-183. Disponível em:

<http://www.marilia.unesp.br/Home/Publi cacoes/politica-de-indexacao_ebook.pdf $>$. Acesso em: 03 nov. 2015.

; FUJITA, Mariângela Spotti Lopes; BOCCATO, Vera Regina Casari. Elaboração do manual de política de indexação na formação continuada do catalogador. In: GIL LEIVA, Isidoro; FUJITA, Mariângela Spotti Lopes (Ed.). 
Política de Indexação. São Paulo:

Cultura Acadêmica; Marília, SP: Oficina

Universitária, 2012. cap. 9, p. 217-228.

Disponível em:

<http://www.marilia.unesp.br/Home/Publi cacoes/politica-de-indexacao_ebook.pdf $>$.

Acesso em: 23 mar. 2015.

SOUSA, Brisa Pozzi de; FUJITA,

Mariângela Spotti Lopes. Análise de assunto no processo de indexação: um percurso entre teoria e norma.

Informação \& Sociedade: Estudos, João Pessoa, v. 24, n. 1, p. 19-34, jan./abr. 2014. Disponível em:

<http://www.ies.ufpb.br/ojs/index.php/ies/ article/download/16281/10872>. Acesso em: $11 \mathrm{dez} .2015$.

SOUZA, Maria Naires Alves de et al. Indexar para quem? Ou o conflito entre a linguagem natural versus linguagem controlada. In: CONFERÊNCIA INTERNACIONAL SOBRE SISTEMAS DE INFORMAÇÃO E GESTÃO DE TECNOLOGIA - CONTECSI, 12., 2015, São Paulo. Anais eletrônicos... [São Paulo, 2015]. 17 p. Disponível em: <http://www.contecsi.fea.usp.br/envio/ind ex.php/contecsi/12CONTECSI/paper/vie w/2458/2264 >. Acesso em: 11 dez. 2015.
STREHL, Letícia. Avaliação da consistência da indexação realizada em uma biblioteca universitária de artes.

Ciência da Informação, Brasília, v. 27, n. 3, p. 329-335, set./dez. 1998.

Disponível em:

<http://www.scielo.br/pdf/ci/v27n3/27n3a 11.pdf>. Acesso em: 30 nov. 2015.

UNIVERSIDADE FEDERAL DO

CEARÁ. Biblioteca Universitária

(Comissão de Catalogação). Política de

Indexação do Sistema de Bibliotecas da Universidade Federal do Ceará.

Fortaleza, 2016. Disponível em:

$<$ http://www.biblioteca.ufc.br/images/arq uivos/documentos_tecnicos/politica_inde xacao_BU-UFC_09_04_2016.pdf >. Acesso em: 14 maio 2016.

VAN DER LAAN, Regina Helena; ALVORCEM, Rochelle Martins. A terminologia expressa no discurso dos especialistas da área da Ciência da Informação: um estudo de caso. Revista

Brasileira de Biblioteconomia e Documentação, Nova Série, São Paulo, v. 3, n. 2, p. 107-115, jul./dez. 2007. Disponível em:

<http://www.febab.org.br/rbbd/ojs2.1.1/index.php/rbbd/article/viewFile/53/5 4>. Acesso em: 15 dez. 2015. 